\title{
CAD and FEM Modelling of Theoretical Roughness in Diamond Burnishing
}

\author{
Csaba Felhö ${ }^{1}$. $\cdot$ Gyula Varga ${ }^{1}$
}

Received: 17 September 2021 / Revised: 7 January 2022 / Accepted: 20 January 2022 / Published online: 18 February 2022

(c) The Author(s) 2022

\begin{abstract}
Diamond burnishing is a widely used finishing machining that can have a positive effect on both the roughness of cut surfaces and its stress state. This paper is focused on the examination of the theoretical and real roughness of surfaces machined by sliding burnishing. In determining the theoretical roughness, the surface structure created by the pre-burnishing cutting (turning) was also considered. Two different modelling methods were used to obtain theoretical surface roughness data: CAD-modelling and finite element simulation. A method using CAD-based modelling of the machined surface was used to determine the theoretical roughness for both the turning and burnishing processes. However, this previously developed model is not directly applicable to plastic deformation processes such as diamond burnishing, so the principle of the Hertz theory for normal contact of elastic solids was used to calculate the penetration depth of the tool into the workpiece. The 2D FEM simulations were performed in the DEFORM software. To validate the applied modelling methods, real cutting experiments were performed, where the surface roughness values were measured during diamond burnishing experiments with different feed per revolution values. Based on the comparison of both applied modelling methods with real roughness data it can be stated that the theoretical roughness values are well approximated the real data.
\end{abstract}

Keywords Sliding burnishing · Surface roughness in burnishing · Theoretical roughness is burnishing · CAD-based modelling of surface roughness $\cdot$ Hertz-theory-based modelling of surface roughness

\section{Introduction}

Diamond burnishing is a versatile plastic deformation-based machining method which can be used for several purposes. It can be used to improve the smoothness of previously cut surfaces [1], to optimize its mechanical surface quality properties like hardness and residual stresses (by turning its tensile stress into a more advantageous compressive stress [2]) and it even have the possibility to increase their corrosion resistance as well $[3,4]$. The burnishing process can follow the turning [5] (or hard turning [6]) process immediately thereby replacing the need for grinding [7], or after the grinding process, so about complementing it [8]. There are essentially two different types of burnishing: slide burnishing [9] (or simply diamond burnishing) and roller burnishing [10]. The choosing from these two methods sometimes is not easy,

Csaba Felhő

csaba.felho@uni-miskolc.hu

1 Institute of Manufacturing Science, University of Miskolc, Egyetemváros, Miskolc 3515, Hungary as they have many common characteristics, but essentially the roller burnishing is the first choice, and the diamond burnishing may be used in such scenarios, where the roller burnishing cannot be applied: e.g. to finish hardened materials (due to the relatively large contact area in case of roller burnishing, that process cannot be used optimally is this case), or to finish internal or external surfaces with such contours that cannot be roller-burnished. The burnishing process is not limited to finish only shafts; it can be used for many other types of surfaces: for holes [11], for flat surfaces [12] and many other more complex geometries as well [13]. It can be even combined with other machining methods, like with milling in [14] or with turning [15]. In [16] a special process variant, the so-called cryogenic slide burnishing was utilized; the aim was to optimize the process parameters to find minimum surface roughness and maximum surface hardness for machining of 17-4 precipitation hardenable steel. It was shown before in [17] that the cryogenic cooling may have positive impacts on the surface roughness, residual stresses, hardness and wear characteristics of the burnished surface. Burnishing can be considered as an environmentally 
friendly alternative for the grinding process as well [18]. To investigate the effects of the diamond burnishing process on the machined surface, it is essential to examine the generated surface roughness, which allows for the performance qualification of the respective process. A possible solution for that is the measurement and simulation of the surface roughness profile which can be obtained with the applied process parameters. Due to the fact, that it is a chipless finishing operation, the simulation of its theoretical roughness is not as straightforward, as with other chip removal processes, e.g., turning or milling. On the other hand, the tool has a defined edge geometry, which allows for the analytical calculation of the theoretical surface profile, which is not that easy in case of abrasive processes, like grinding [19].

It can be seen from the above that the study of surface roughness is of great importance in the diamond burnishing process, which is why many researchers have already addressed this topic. In the following, some of the recent typical approaches that the authors find more interesting are presented.

Saldana-Robles et al. [20] used RSM and factorial experimental designs to investigate the effect of process parameters on surface roughness, hardness, and corrosion resistance of AISI 1045 steel. Experimental and FEM tests were performed on the sliding burnishing of AISI 316Ti chromiumnickel steel by Maximov et al. [21] to determine the effect of tool tip radius and burnishing force on surface roughness, microhardness, residual stress, fatigue strength and wear resistance of the machined surfaces. It has been found that this method of machining has a beneficial effect on all the characteristics listed. Similar results were obtained when analysing the slide burnishing of hourglass-shaped tensile specimens made of $41 \mathrm{Cr} 4$ steel [22]. Fedorovic et al. [23] used finite element studies to determine the optimal technological parameters for both diamond and ultrasonic burnishing processes.

Korzynski [24] has previously shown that although diamond burnishing is considered primarily as a finishing process, it can in fact be performed for several purposes by appropriate selection of the governing parameters: smoothing (to achieve good surface finish), hardening (to improve the hardness of the surface layer), dimensional (to change the dimensions of the workpiece) and mixed (for several purposes from the above). Maximov et al. [25] have classified the applied variants as smoothing, deep or mixed burnishing, and they optimized the main process parameters (diamond radius, burnishing force) applicable to each variant during the machining of $41 \mathrm{Cr} 4$ steel. Based on the results of experiments Korzynski et al. [26] have showed that there are correlations between the three-dimensional roughness parameters in diamond burnishing, so it is sufficient to evaluate some of the roughness parameters when examining the process. Furthermore, correlation equations were determined to estimate some roughness indexes based on the technological parameters for diamond burnishing of 317Ti stainless steel. Amini et al. [27] have developed a 3D numerical finite element model for the ball burnishing of ball-end milled surfaces. The novelty of their approach was that the model includes the target workpiece real surface integrity descriptors resulting from a ball-end milled AISI 1038 surface. Kluz et al. [28] have used Artifical Neural Networks (ANNs) to estimate the expected value of surface roughness for sliding burnishing of $42 \mathrm{CrMo} 4$ heat-treated steel with polycrystalline diamond and cemented carbide tip tools. Nguyen et al. [29] have dealt with the energy-efficient optimization of burnishing process of SKD61 steel to reduce the energy consumption while improving the surface roughness and the hardness of the workpiece at the same time. Sachin et al. [30] has made a correlation model between process parameters and surface roughness and hardness as outputs in MQL (Minimum Quantity Lubrication) burnishing of 17-4 precipitation hardenable stainless steel using response surface methodology and a multi-objective Genetic Algorithm (GA). Nagorkin et al. [31] investigated how the so-called "technological heredity" can be taken into account in estimating roughness values in diamond burnishing.

This paper is focused on the investigation of the evolution of surface roughness after diamond burnishing of surfaces which were machined by turning before.

\section{Materials and Methods}

An experimental, and two different modelling methods (CAD and FEM-based) were used during the investigations to obtain the roughness profiles the burnished surfaces. Each of these is described in detail below.

The first method is a based on CAD modelling: a previously developed CAD-based modelling method of the machined surface [32] was applied to generate the theoretical surface profiles after diamond burnishing. However, it should be noted, that this method was originally developed for such material removal processes as turning or milling, so a special calculation method (which is based on the Hertztheory) was used here to adapt it for diamond burnishing. The third method is based on finite element method: a FEM software was used to model the diamond burnishing process, and the generated surface profile was exported from the FEM system to a roughness evaluation software, where the roughness parameters can be calculated. After the theoretical investigations, real cutting experiments were conducted, where the machined surfaces were measured both after turning and after burnishing. Therefore, we have the base roughness data, which can be used to validate the previous theoretical simulations. The general overview of the process is shown in Fig. 1. 


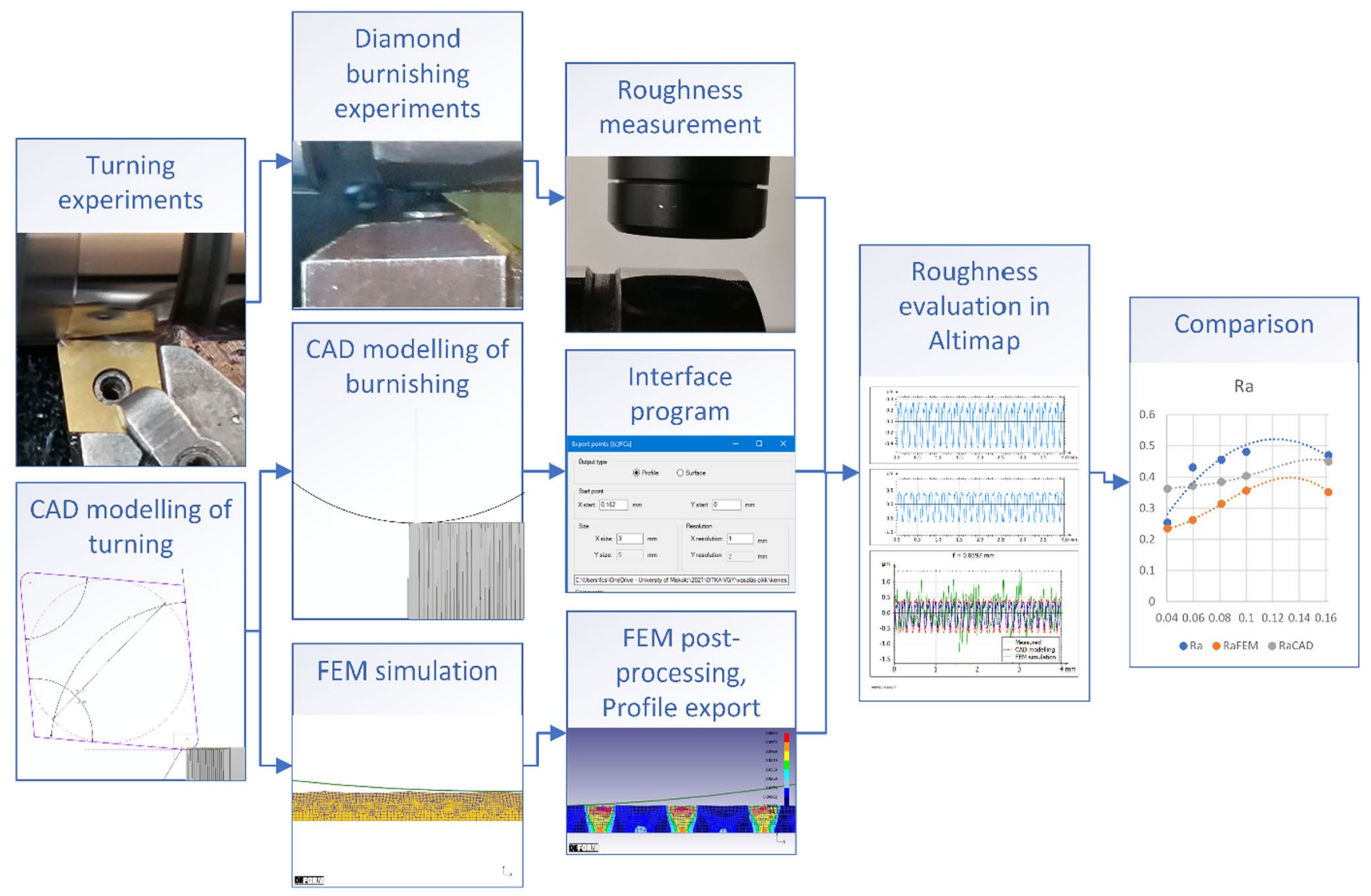

Fig. 1 Overview of the applied investigation method

In all three methods, the diamond burnishing was investigated after the turning process of cylindrical parts as it can be seen on Fig. 1. The diameter of the test workpieces was $\mathrm{D}=47 \mathrm{~mm}$ both in modelling and in experimental runs. The turning operation was performed by a CNGA insert with nose radius of $0.8 \mathrm{~mm}$, the applied feed per revolution value was $0.15 \mathrm{~mm}$. The diamond burnishing was done by a spherical slide burnishing tool with a tip radius of $3.5 \mathrm{~mm}$. The burnishing force was set to $60 \mathrm{~N}$. The feed values were altered, the following values were used: $\mathrm{f}=0.0203 ; 0.0406$; 0.0597; 0.0812; $0.1 \mathrm{~mm}$.

\subsection{CAD-Based Modelling of the Surface Roughness in Diamond Burnishing}

A modelling method was developed formerly to calculate the theoretical surface topography for cutting with tools having defined edge geometry [32]. This model is based on the CAD modelling of the workpiece and the tool, and to model the kinematics of the process as well. It can be used to generate the theoretical cut surface topography in face milling, turning, etc. [33]. The modelling can be performed in essentially any $3 \mathrm{D}$ CAD system, the Autodesk Inventor software was utilized here. Every cutting method needs a tailored CAD model that mimics the kinematics of the real cutting process. The main task to be solved after the 3D model creation is to export the points (coordinates) of this surface into a special file format which can be used to evaluate the data according to the requested roughness parameters. Therefore, a special interface program was developed for the Autodesk Inventor system, which can query the surface points and save them into the SURF file format. The created data file can be loaded in the AltiMap surface roughness evaluation software (which is commercial evaluation software for the Altimet 520 3D roughness measurement machine used in the roughness measurements), where the standard surface roughness parameters can be evaluated [34]. However, this previously developed method cannot be utilized directly for diamond burnishing. Although the definite edge geometry is also true here, this process is based on plastic formation essentially. Thus, there is no preset depth of cut in this case, but the tool is pressed against the surface of the workpiece with a certain force value. Furthermore, since in the case of burnishing the previously machined (in this case turned) surface is formed without chip removal, the surface created by it cannot be modelled on its own, it is necessary to model the surface which was created (cut) by the previous operation [35]. Therefore, the turned surface was created at first during the modelling and then the burnished one. For the 
modelling of the burnishing process, the penetration depth of the tool has to be calculated at first, which was performed according to the Hertz theory for normal contact of elastic solids [36]. Here, the $\delta$ normal displacement of the contact area corresponds to the sought penetration depth. This can be calculated from the following data: the normal force, the two radiuses (radii of the tool and the workpiece), the Young's modulus and the Poisson's ratio of the workpiece and the tool. The respective material properties were selected according to the used workpiece material, which was 30CRMO4 (1.7220). The applied parameters for the calculation and the results are summarized in Table 1.

The name of the symbols used in Table 1:

- F: Normal force, [N];

- $\mathrm{R}_{1}$ : Radius of the workpiece, $[\mathrm{mm}]$;

- $\mathrm{R}_{2}$ : Radius of the burnishing tool, [mm];

- $\nu_{1}$ : Poisson's ratio of the workpiece;

- $v_{2}$ : Poisson's ratio of the tool;

- $\mathrm{E}_{1}$ : Young modulus of the workpiece, $\left[\mathrm{N} / \mathrm{mm}^{2}\right]$;

- $\mathrm{E}_{2}$ : Young modulus of the tool, $\left[\mathrm{N} / \mathrm{mm}^{2}\right]$;

- $\varphi$ : Angular parameter, should be calculated according to Eq. 6 in [36], $\left[^{\circ}\right]$;

- $\mathrm{m}$ and $\mathrm{r}$ : contact parameters, can be obtained from Fig. 7 in [36];

- $\mathrm{K}_{1}$ and $\mathrm{K}_{2}$ material parameters, can be calculated by Eqs. 4 and 5 in [36];

- a: Semi-axis of the contact surface, see Eq. 2 in [36], [mm];

- $\delta$ : normal displacement, see Eq. 3 in [36], [ $\mu \mathrm{m}]$.

As it can be seen in Table 1, the penetration depth was calculated as $2.24 \mu \mathrm{m}$. This of course, assumes idealised contact situation, but it can be a good starting point for the $\mathrm{CAD}$ modelling.

\subsection{Finite Element Modelling of Surface Roughness in Diamond Burnishing}

Finite element modeling of burnishing is a great help for more accurate theoretical modeling of the processes that take place during machining. It is especially important in case of machining methods which are based on plastic deformation, like diamond burnishing. As it was introduced in Fig. 1, the FEM modelling was performed by using the surface profile which was generated by CAD modelling of the turning process. Borysenko et al. [37] has showed, how important is to try to create a FEM model for burnishing which simulates the real surface structures as much as possible. Therefore, they have used the measured workpiece and tool surfaces for the FEM simulations. However, in case of such deterministic processes as turning, the created roughness profile is fairly regular, so the theoretical profile which was created by CAD modelling in the previous step could be utilized without any reasonable simulation errors. Moreover, it should be considered, that the surface has to be meshed during the FEM model preparation, and if the real surface structure is taken into account without filtering, a significant amount of the surface features will be lost during the meshing process or otherwise a pointlessly small mesh size would have to be set. If a high-pass filter is used, the surface may end up in something which is quite close to the theoretical one.

The DEFORM finite element software was utilized for the simulations. Since the point here was to obtain a roughness profile from the FEM investigations, 2D simulations were performed, which is significantly faster than the modelling of the process in 3D. However, the 2D modelling of diamond burnishing of cylindrical parts is not so straightforward: in the applied work plane, the spherical tool (whose twodimensional projection is a circular arc) will press and form the shape of the workpiece at every $f$ step (see Fig. 2). This modeling method has already been used by many researchers with good results: e.g. Stöckmann and Putz [38] have applied this method for flat surfaces, while John et al. [39] has used it for turning. This is an approximate simulation of the burnishing process, but-according to the referenced works - seems to be adequate for $2 \mathrm{D}$ roughness calculations. In order to perform that type of modelling in DEFORM, a multi-operation simulation was utilized in the system: the tool is pressed against the workpiece with the specified force

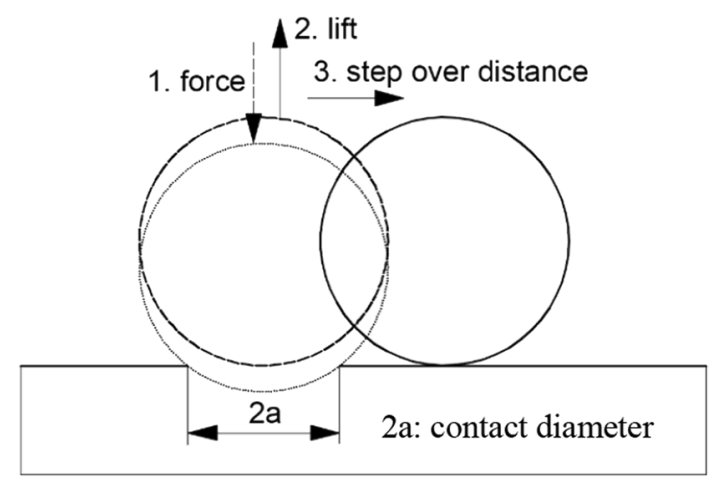

Fig. 2 Development of the burnished surface geometry [38]

Table 1 The applied parameters and the results of the Hertz-theory calculation

\begin{tabular}{llllllllllllll}
\hline $\mathrm{F}[\mathrm{N}]$ & $\mathrm{R}_{1}[\mathrm{~mm}]$ & $\mathrm{R}_{2}[\mathrm{~mm}]$ & $\nu_{1}$ & $\nu_{2}$ & $\mathrm{E}_{1}\left[\mathrm{~N} / \mathrm{mm}^{2}\right]$ & $\mathrm{E}_{2}\left[\mathrm{~N} / \mathrm{mm}^{2}\right]$ & $\varphi\left(^{\circ}\right)$ & $\mathrm{m}$ & $\mathrm{r}$ & $\mathrm{K}_{1}$ & $\mathrm{~K}_{2}$ & $\mathrm{a}[\mathrm{mm}]$ & $\delta[\mu \mathrm{m}]$ \\
\hline 60 & 47 & 3.5 & 0.28 & 0.18 & $2 * 10^{5}$ & $1.13 * 10^{6}$ & 88 & 1 & 1 & $1.15^{*} 10^{-6}$ & $2.31^{*} 10^{-7}$ & 0.087 & 2.24 \\
\hline
\end{tabular}


value for a time of $0.01 \mathrm{~s}$, and then the tool is released, and moved by the $f$ value to the next position along the workpiece, where this process continues.

The tool was modelled as a rigid body: it has a diamond tip, which is hard enough to not to significantly deform during the process. The workpiece was modelled as an elastoplastic object. The material of the workpiece was selected as AISI4140 from the system library. The workpiece mesh has had 2115 elements with 2260 nodes. The mesh was fined near of the top of the surface, to obtain more accurate results. The maximum element size was set to $0.0071 \mathrm{~mm}$, while their minimum size was set at around $1 \mu \mathrm{m}$.

Figure 3 shows a representative example from the simulations: the left hand side of the figure, the initial surface can be seen, which was obtained from the CAD modelling of the turning operation. The two feed values were: $\mathrm{f}_{\text {turn. }}=0.15 \mathrm{~mm}$ (feed per revolution for turning), $\mathrm{f}_{\text {burn. }}=0.1 \mathrm{~mm}$ (feed per revolution for burnishing). The right side of the figure shows the surface after the burnishing process: the tool was pushed against the workpiece at every $\mathrm{f}_{\text {burn. }}$ distance from the start, within the simulated length. As it can be also observed from the figure, three turned profile cusps were simulated, and then the created surface profile was multiplied-after the transfer of the profile points to the roughness evalution software-along the measurement axis in order to obtain the whole required length roughness profile. The DEFORM software allows to export the simulated shape as a DXF file, which was then transformed into coordinate points via the AutoCAD software with the help of a small script. This text file of pure coordinates was imported into the Altimap surface roughness evaluation software, where the patterning (multiplication of the short profile elements) and the evaluation of the roughness profile was done.

\subsection{Real Machining Experiments}

After the theoretical investigations, the physical experiments were performed, the results of which could be used as basic data to validate the simulation results. Here again, it was necessary to perform two series of experiments. First, the specimens were machined by turning, during which the surface was prepared for subsequent diamond burnishing using expediently selected cutting parameters. This means that such cutting data were used that gave generally good turned surface quality: $\mathrm{v}_{\mathrm{c}}=265 \mathrm{~m} / \mathrm{min}, \mathrm{f}=0.15 \mathrm{~mm}, \mathrm{a}_{\mathrm{p}}=0.1 \mathrm{~mm}$. The applied cutting tool was a CBN insert with CNGA geometry. In the next step, the diamond burnishing was performed with a diamond-tip burnishing tool which has a radius of $\mathrm{R}=3.5 \mathrm{~mm}$. The applied technological parameters were the following: $n=3751 / \mathrm{min}$.; $F=60 \mathrm{~N} ; \mathrm{f}=0.0203$; $0.0406 ; 0.0597 ; 0.0812$ and $0.1 \mathrm{~mm}$.

Both the turning and the diamond burnishing tests were conducted on an EU-400-01 lathe machine. This is a traditional lathe machine with high rigidity, and a completely new rotating centre was used to support the workpiece from the tailstock. The applied lubricant during the diamond burnishing was a SAE $15 \mathrm{~W}-40$ grade traditional oil. The test samples were $\varnothing 47 \mathrm{~mm}$ rods made from 30CRMO4 (1.7220) steel in quenched and tempered state. Its hardness was measured at around $53 \mathrm{HRC}$. As the varied parameter was the feed per revolution value, the work part has to be prepared for the feed change, thus $5 \mathrm{~mm}$ wide grooves were cut after every measurement area, which was $20 \mathrm{~mm}$ long, as it can be seen in Fig. 4, which shows a snapshot from the burnishing experiments.

The surface roughness measurements were made on an Altisurf 520 three-dimensional surface roughness measurement device. The applied probe was a CL2 type Confocal Chromatic Sensor (CCS), with an MG140 magnifier. The measurement range of this setup is $300 \mu \mathrm{m}$, while the theoretical resolution is up to $0.5 \mathrm{~nm}$. The measurement parameters were set according to the ISO 4288 standard.

\section{Results and Discussion}

As it was mentioned before, the first step was to model the roughness of the turned surfaces, which creates a regular profile. Since the feed value was the same for all surfaces $\left(\mathrm{f}_{\text {turn. }}=0.15 \mathrm{~mm}\right)$, their initial theoretical roughness values are also the same. The modelled and the measured roughness profiles for the turning operation are shown in Fig. 5.

The average values for the measured surface roughness after turning were $\mathrm{Ra}=0.453 \mu \mathrm{m}$ and $\mathrm{Rz}=2.534 \mu \mathrm{m}$. The theoretical values for the modelled surfaces were $\mathrm{Ra}=0.899 \mu \mathrm{m}$ and $\mathrm{Rz}=3.51 \mu \mathrm{m}$. It can be noticed here that the theoretical values are higher than the measured ones,
Fig. 3 2D FEM simulation of diamond burnishing

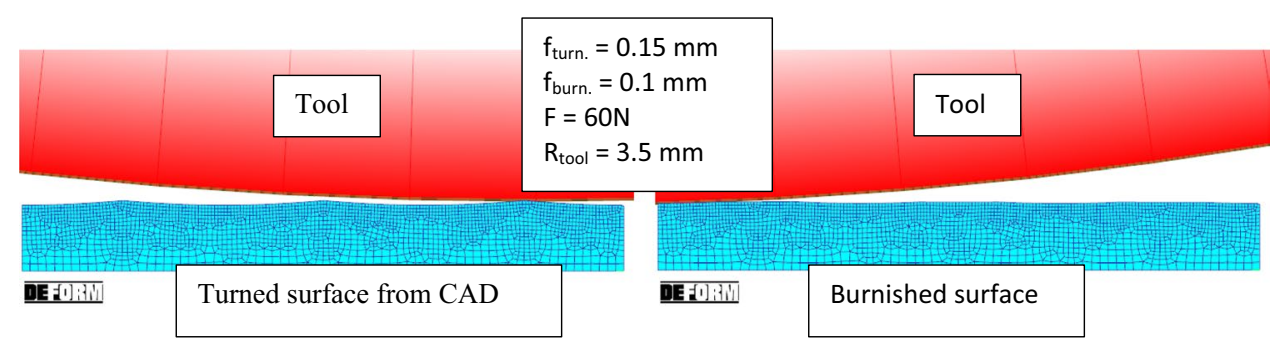

Springer K与尸트 


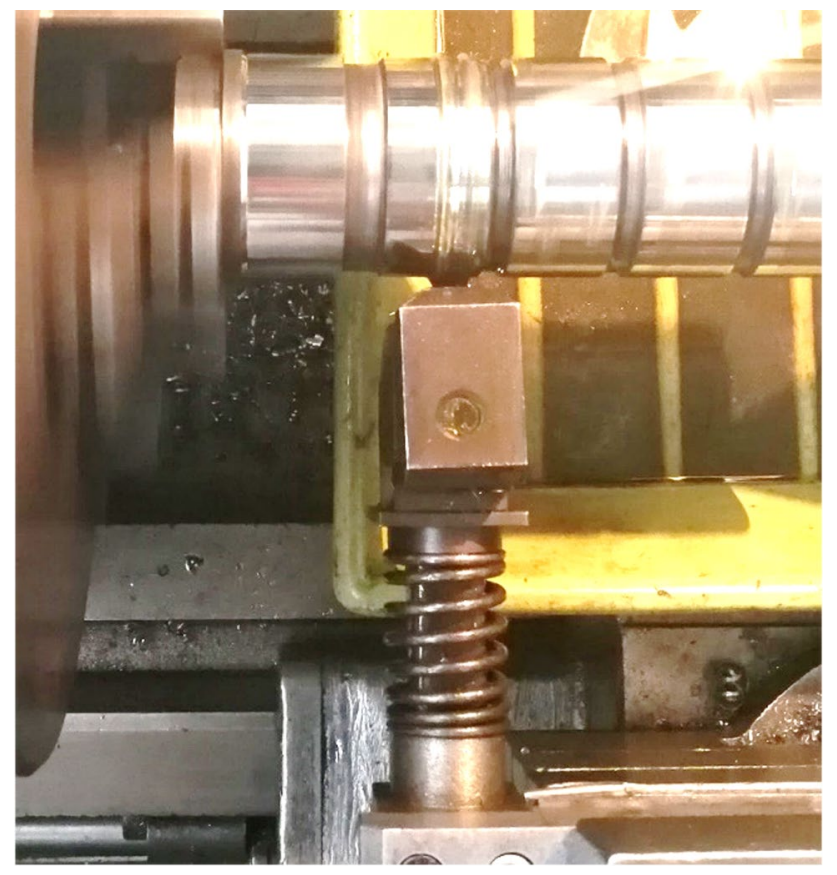

Fig. 4 The cutting experiment set-up

which can be considered a common phenomenon for tools with notable tip radii [40].

Figure 6 shows the three roughness profiles for every investigated feed: the green one is the measured profile, which was recorded after the physical cutting experiments. It should be noted here that the micro-roughness was filtered out from these profiles in order to be able to compare the graphical results better. The red ones are the theoretical profiles which were generated by CAD modelling. For the CAD modelled and the FEM simulated profiles it was not necessary to apply a filter, as they do not contain any disturbances to be filtered out due to the specificity of the modeling and simulation procedures used. Finally, the blue graphs on the data series illustrate the roughness profiles formed as results of the FEM simulations.

Based on these results, the following findings could be made: At the lowest feedrate, the theoretical roughness profiles (which means both the CAD and FEM results here) are fairly regular. There are some differences between the profiles produced using CAD modelling and by FEM simulation, which occurred due to the differences between the two methods. In CAD modelling, the profile of the burnishing tool was cut out of the pre-turned profile with the penetration depth calculated by the Hertz-theory calculation, and due to the small feed, regular small incisions are actually visible at the top of the profile. In FEM modeling, on the other hand, the software calculates the indentation at the current position under the given conditions. For this reason, the profile is also more dynamic, taking into account the actual contact conditions between the tool and the workpiece surfaces. This means, that if the actual contact area is smaller, then the tool will penetrate deeper into the workpiece, and this contact area will change from point to point. Apart from this, of course, the FEM profile is also regular. On the other hand, the measured profile is, as usual, irregular but periodic. In case of such a dynamic process than diamond burnishing, where there is no chip formation, and the burnishing force is relatively small, the generated surface will be undoubtedly somewhat irregular. Another important factor which may be considered as well is the surface topography of the burnishing tool tip. Borysenko et al. [37] has also taken this into account in their FEM simulations. However, it should be mentioned, that if a relatively new burnishing tools is used, then this difference may be not so significant (however the investigation of this may be the next step forward in this research). Looking at the profile diagrams for the following feed value at $\mathrm{f}=0.0406 \mathrm{~mm}$, it can be concluded that the theoretical profiles are similarly regular in shape while the measured profile is even more irregular, in fact, it seems to be the most irregular at this feed. But this is only a subjective finding of the authors after the visual examination, it is worth considering the numerical results for the final evaluation of the data. The further diagrams show that as the value of the burnishing feed increases, the theoretical roughness profiles become more and more irregular, and obviously there is also a kind of increase in the cusp heights of the profiles, although this (a) $\mu \mathrm{m} \uparrow$

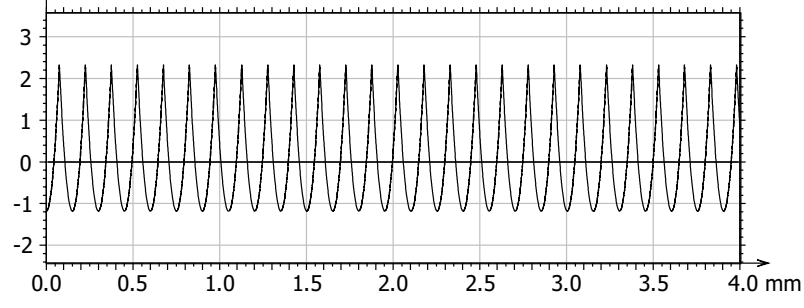

(b) $\mu \mathrm{m}$

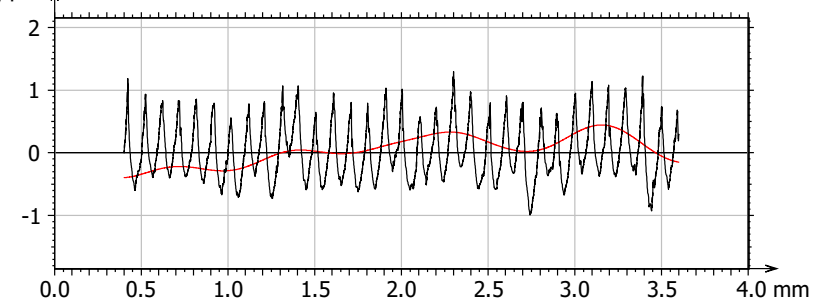

Fig. 5 Modelled (a) and measured (b) roughness profiles for turning 

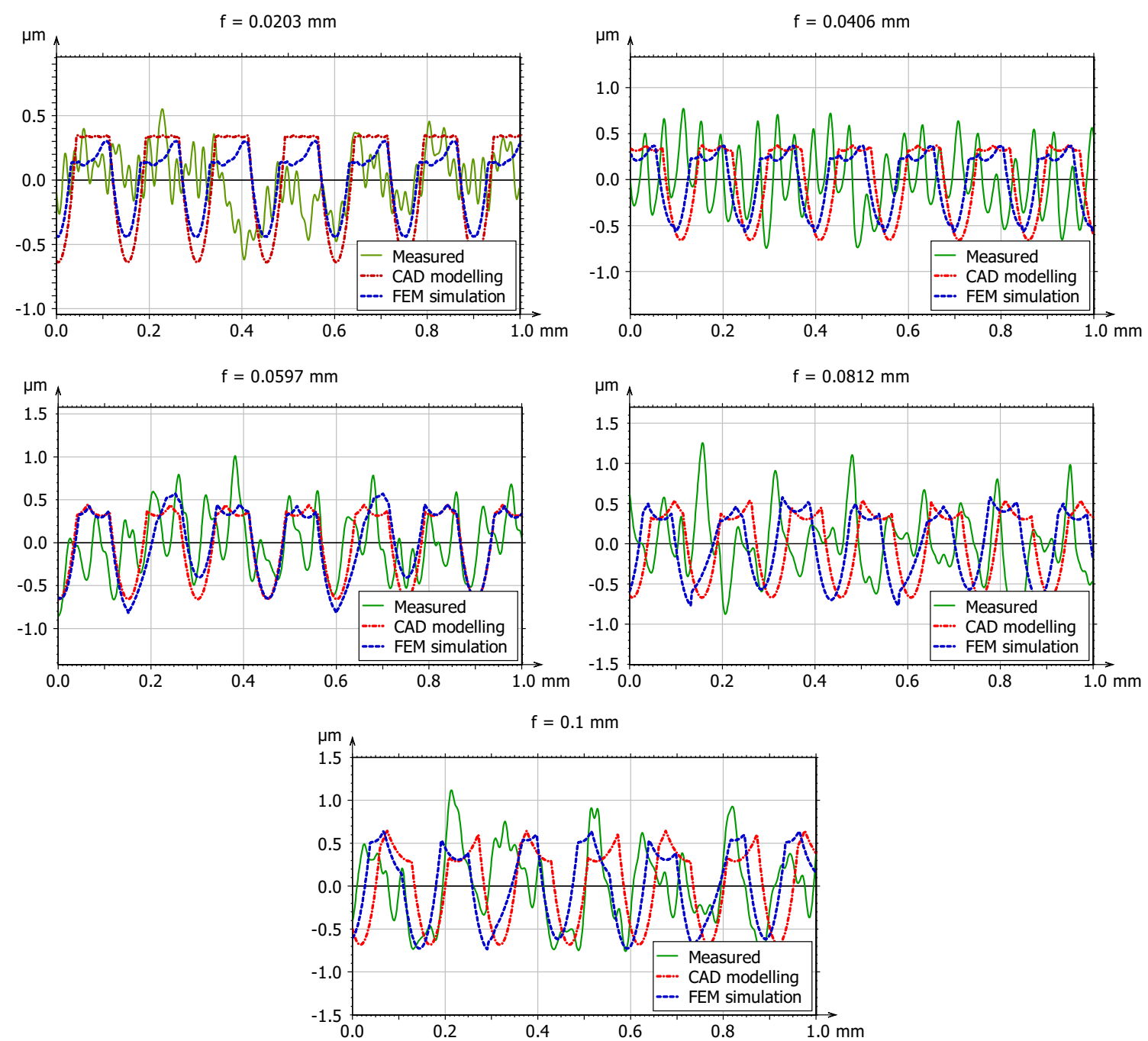

Fig. 6 Comparison of the modelled, simulated and measured roughness profiles for different feed values

is no longer significant after the $\mathrm{f}=0.597 \mathrm{~mm}$ feed value. This may suggest, that as the feed per revolution value gets closer to the feed of the previous operation (in this case the turning), the roughness will not deteriorate significantly with the feed increase. However, it is not recommended to perform the burnishing process with too high feed values as it is a finishing operation, and its main goal is to improve the surface finish of the part. The $\mathrm{f}=0.0406 \mathrm{~mm}$ and $0.0597 \mathrm{~mm}$ values seem to be like preferable feeds for this operation.

It can also be observed that the wavelength of the roughness profile does not change significantly with increasing burnishing feed. This is one of the features of the diamond burnishing process. As the wavelength of the surface roughness profile on the machined surface is mainly determined by the pre-burnishing operation (which in the present investigation is the turning), this can be influenced by changing its feedrate, but that was constant during the current research. The burnishing only smoothes out the previously formed roughness peaks, the wavelength no longer changes substantially.

Figure 7 shows the comparison of the investigated $\mathrm{Ra}$ and $R z$ roughness index values for the three data sets: measured values are denoted as Ra and Rz, and the CAD and FEM values are indicated by their names in subscripts. As it is obvious from the graph for $\mathrm{Ra}$, the measured and the CAD modelled values are actually very close to each other, while the FEM results are getting closer to them after $\mathrm{f}=0.0597 \mathrm{~mm}$. Below that feed value, the FEM simulation gave somewhat lower values, and this may be attributed to the fact, that the roughness profiles seen in Fig. 6 for $\mathrm{f}=0.0203$ and $0.0406 \mathrm{~mm}$ feed values are somewhat more "peaked", so their average will be lower. This is also supported by the $\mathrm{Rz}$ graph: there is no significant difference between the CAD and FEM values for these low feed data. The measured $\mathrm{Rz}$ is greater though, but this is attributed to the characteristics of 

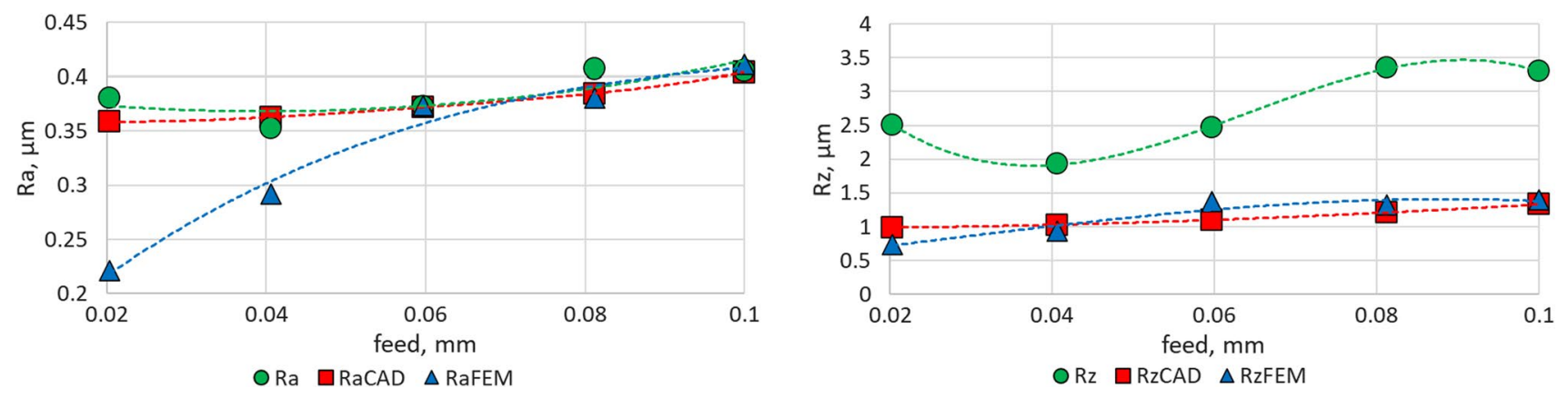

Fig. 7 Comparison of the $\mathrm{Ra}$ and $\mathrm{Rz}$ roughness parameters for the three datasets

the real surface at the first place: as it was already mentioned before, it has much greater irregularities, and as the Rz takes the five high points and the five valley bottoms, therefore it will be obviously greater. It should be also noted here, that the Rz may be better to be used to describe ground or similar surfaces. For deterministic processes, like turning and burnishing, the $\mathrm{Ra}$ arithmetical average height roughness parameter seems to be much more satisfying [41]. Starting from a feed value of $\mathrm{f}=0.0597 \mathrm{~mm}$, the values of $\mathrm{Ra}$ are essentially the same for all three data sets, the points on the graph overlap in several cases. This applies to CAD and FEM data for Rz, but for the whole investigated range.

\section{Conclusions}

The conducted investigations are essentially concluded that the CAD modelling method combined with the Hertz theory calculation seems to be a good approximation of the burnishing process, or at least it is not significantly worse, than the applied FEM method.

The main results of the performed modelling and experimental studies:

- It was found that the modelled and actual values correlated relatively well. In the case of the roughness parameter $\mathrm{Ra}$, the results obtained with increasing the feedrate became more and more close to the real roughness values. With CAD modelling-based calculation, a better correlation was found with real roughness data in almost all cases than with FEM.

- For the Rz parameter, the measured roughness values were higher than the simulation results in all cases. The reason for this was thought to be discovered in the nature of the surface and this roughness parameter: The depicted roughness diagrams show that the real surfaces have significant protrusions which have a much more significant effect on roughness peak-dependent parameters such as $\mathrm{Rz}$ than on the arithmetic mean values of Ra.
- The wavelengths of the roughness profiles obtained after sliding burnishing were found to be independent of the value of the burnishing feed. The reason for this was that the wavelength of the roughness profile is primarily determined by the pre-burnishing operation (in this case turning), the burnishing process only smoothes the roughness peaks, which can be clearly seen in the roughness profiles presented in the paper.

- It may be noted that both the FEM simulation and the CAD modelling takes some simplifications into account, which may mean that the results achieved are encouraging, but should not be seen as universal. The area of diamond burnishing is an area with an enormous amount of untapped potential, where many more interesting results can be expected. In the future, the authors intend to continue the studies primarily in the direction of threedimensional FEM modeling, using the actual measured surfaces and the real tool geometry.

Acknowledgements This work has been supported by Project no. NKFI-125117, which has been implemented with the support provided from the National Research, Development and Innovation Fund of Hungary, financed under the K_17 funding scheme.

Funding Open access funding provided by University of Miskolc.

Open Access This article is licensed under a Creative Commons Attribution 4.0 International License, which permits use, sharing, adaptation, distribution and reproduction in any medium or format, as long as you give appropriate credit to the original author(s) and the source, provide a link to the Creative Commons licence, and indicate if changes were made. The images or other third party material in this article are included in the article's Creative Commons licence, unless indicated otherwise in a credit line to the material. If material is not included in the article's Creative Commons licence and your intended use is not permitted by statutory regulation or exceeds the permitted use, you will need to obtain permission directly from the copyright holder. To view a copy of this licence, visit http://creativecommons.org/licenses/by/4.0/. 


\section{References}

1. Buldum, B. B., \& Cagan, S. C. (2018). Study of ball burnishing process on the surface roughness and microhardness of AZ91D alloy. Experimental Techniques, 42, 233-241. https://doi.org/10. 1007/s40799-017-0228-8

2. Korzynski, M., Pacana, A., \& Cwanek, J. (2009). Fatigue strength of chromium coated elements and possibility of its improvement with slide diamond burnishing. Surface \& Coatings Technology, 203, 1670-1676. https://doi.org/10.1016/j.surfcoat.2008.12.022

3. Al-Qawabeha, U., Al-Rawajfeh, A. E., \& Al-Shamaileh, E. (2009). Influence of roller burnishing on surface properties and corrosion resistance in steel. Anti-Corros Methods Mater, 56, 261-265. https://doi.org/10.1108/00035590910989552

4. Konefal, K., Korzynski, M., Byczkowska, Z., \& Korzynska, K. (2013). Improved corrosion resistance of stainless steel X6CrNiMoTi17-12-2 by slide diamond burnishing. Journal of Materials Processing Technology, 213, 1997-2004. https://doi. org/10.1016/j.jmatprotec.2013.05.021

5. Kumar, K., \& Prasad, K. E. (2015). Application of roller burnishing process for final machining of cilindrical surface. IOSR Journal of Mechanical and Civil Engineering (IOSR-JMCE), 12, 01-07. https://doi.org/10.9790/1684-12110107

6. Grzesik, W., \& Zak, K. (2013). Producing high quality hardened parts using sequential hard turning and ball burnishing operations. Precision Engineering, 37, 849-855. https://doi.org/10. 1016/J.PRECISIONENG.2013.05.001

7. Luca, L., Marinescu, I., \& Neagu-Ventzel, S. (2002). Burnishing versus grinding for automotive parts. AMST'02 Advanced Manufacturing Systems and Technology. https://doi.org/10. 1007/978-3-7091-2555-7_48

8. Slavov, S. D., Dimitrov, D. M., \& Konsulova-Bakalova, M. I. (2021). Advances in burnishing technology. Advanced Machining and Finishing. https://doi.org/10.1016/B978-0-12-8174524.00002-6

9. Maximov, J. T., Duncheva, G. V., Anchev, A. P., \& Ichkova, M. D. (2019). Slide burnishing-review and prospects. International Journal of Advanced Manufacturing Technology, 104, 785-801. https://doi.org/10.1007/s00170-019-03881-1

10. Hemanth, S., Harish, A., Nithin Bharadwaj, R., Bhat, A. B., \& Sriharsha, C. (2018). Design of roller burnishing tool and its effect on the surface integrity of Al 6061. Mater Today Proc, 5, 12848-12854. https://doi.org/10.1016/j.matpr.2018.02.269

11. Akkurt, A. (2011). Comparison of roller burnishing method with other hole surface finishing processes applied on AISI 304 austenitic stainless steel. Journal of Materials Engineering and Performance, 20, 960-968. https://doi.org/10.1007/ s11665-010-9718-x

12. Amdouni, H., Bouzaiene, H., Montagne, A., Van Gorp, A., Coorevits, T., Nasri, M., et al. (2017). Experimental study of a six new ball-burnishing strategies effects on the Al-alloy flat surfaces integrity enhancement. International Journal of Advanced Manufacturing Technology, 90, 2271-2282. https://doi.org/10.1007/ s00170-016-9529-9

13. Travieso-Rodríguez, J. A., Dessein, G., \& González-Rojas, H. A. (2011). Improving the surface finish of concave and convex surfaces using a ball burnishing process. Materials and Manufacturing Processes, 26, 1494-1502. https://doi.org/10.1080/10426 914.2010.544819

14. Kalisz, J., Żak, K., Wojciechowski, S., Gupta, M. K., \& Krolczyk, G. M. (2021). Technological and tribological aspects of millingburnishing process of complex surfaces. Tribology International, 155, 106770. https://doi.org/10.1016/j.triboint.2020.106770

15. Nguyen, T.-T., \& Mia, M. (2020). Modeling and evaluation of energy efficiency of new hybrid turning-burnishing process in terms of surface properties. Energies, 13, 4929. https://doi.org/ 10.3390/en13184929

16. Sachin, B., Rao, C. M., Naik, G. M., \& Puneet, N. P. (2021). Influence of slide burnishing process on the surface characteristics of precipitation hardenable steel. SN Applied Sciences, 3, 223. https://doi.org/10.1007/s42452-021-04260-w

17. Yang, S. (2012). Cryogenic burnishing of Co-Cr-Mo biomedical alloy for enhanced surface integrity and improved wear performance. Doctoral Dissertation. University of Kentucky.

18. Varga, G. (2014). Can diamond burnishing be done in an environmentally friendly way? Applied Mechanics and Materials, 474, 411-416. https://doi.org/10.4028/WWW.SCIENTIFIC.NET/ AMM.474.411

19. Xu, L., Luo, R., Yang, Z., Zha, T., \& Hu, D. (2014). Modelling and experimental analysis of surface roughness in spherical grinding. Proceedings of the Institution of Mechanical Engineers, 228, 856-865. https://doi.org/10.1177/0954405413508944

20. Saldaña-Robles, A., Plascencia-Mora, H., Aguilera-Gómez, E., Saldaña-Robles, A., Marquez-Herrera, A., \& Diosdado-De la Peña, J. A. (2018). Influence of ball-burnishing on roughness, hardness and corrosion resistance of AISI 1045 steel. Surface and Coatings Technology, 339, 191-198. https://doi.org/10.1016/j. surfcoat.2018.02.013

21. Maximov, J. T., Duncheva, G. V., Anchev, A. P., Ganev, N., Amudjev, I. M., \& Dunchev, V. P. (2018). Effect of slide burnishing method on the surface integrity of AISI 316Ti chromium-nickel steel. Journal of the Brazilian Society of Mechanical Sciences and Engineering, 40, 194. https://doi.org/10.1007/s40430-018-1135-3

22. Maximov, J. T., Duncheva, G. V., Anchev, A. P., Dunchev, V. P., \& Ichkova, M. D. (2020). Improvement in fatigue strength of $41 \mathrm{Cr} 4$ steel through slide diamond burnishing. Journal of the Brazilian Society of Mechanical Sciences and Engineering, 42, 197. https:// doi.org/10.1007/s40430-020-02276-8

23. Fedorovich, V., Pyzhov, I., Kundrak, J., Pupan, L., \& Voloshkina, I. (2021). Simulation methodology of diamond burnishing. Advanced Design Simulation Manufacturing. https://doi.org/10. 1007/978-3-030-77719-7_36

24. Korzynski, M. (2007). Modeling and experimental validation of the force-surface roughness relation for smoothing burnishing with a spherical tool. International Journal of Machine Tools and Manufacture, 47, 1956-1964. https://doi.org/10.1016/J.IJMAC HTOOLS.2007.03.002

25. Maximov, J. T., Duncheva, G. V., Anchev, A. P., \& Dunchev, V. P. (2020). Smoothing, deep, or mixed diamond burnishing of lowalloy steel components - optimization procedures. International Journal of Advanced Manufacturing Technology, 106, 1917-1929. https://doi.org/10.1007/s00170-019-04747-2

26. Korzynski, M., Dudek, K., Palczak, A., Kruczek, B., \& Kocurek, P. (2018). Experimental models and correlations between surface parameters after slide diamond burnishing. Measurement Science Review, 18, 123-129. https://doi.org/10.1515/msr-2018-0018

27. Amini, C., Jerez-Mesa, R., Travieso-Rodriguez, J. A., Llumà, J., \& Estevez-Urra, A. (2020). Finite element analysis of ball burnishing on ball-end milled surfaces considering their original topology and residual stress. Metals, 10, 638. https://doi.org/10.3390/ MET10050638

28. Kluz, R., Antosz, K., Trzepieciński, T., \& Bucior, M. (2021). Modelling the influence of slide burnishing parameters on the surface roughness of shafts made of $42 \mathrm{CrMo} 4$ heat-treatable steel. Materials, 14, 1175. https://doi.org/10.3390/ma14051175

29. Nguyen, T.-T., Cao, L.-H., Dang, X.-P., Nguyen, T.-A., \& Trinh, Q.-H. (2019). Multi-objective optimization of the flat burnishing process for energy efficiency and surface characteristics. Materials and Manufacturing Processes, 34, 1888-1901. https://doi.org/10. 1080/10426914.2019.1689266 
30. Sachin, B., Narendranath, S., \& Chakradhar, D. (2019). Selection of optimal process parameters in sustainable diamond burnishing of 17-4 PH stainless steel. Journal of the Brazilian Society of Mechanical Sciences and Engineering, 41, 219. https://doi.org/ 10.1007/s40430-019-1726-7

31. Nagorkin, M. N., Fyodorov, V. P., \& Kovalyova, E. V. (2018). Modeling of process of forming quality parameters for surfaces of parts by diamond burnishing taking into account technological heredity. IOP Conference Series: Materials Science and Engineering, 327, 042071. https://doi.org/10.1088/1757-899X/327/4/ 042071

32. Felhő, C. (2014). Investigation of surface roughness in machining by single and multi-point tools (33rd ed.). Shaker Verlag.

33. Felho, C., \& Kundrak, J. (2014). CAD-Based modelling of surface roughness in face milling. International Journal of Mechanical and Mechatronics, 8, 814-818.

34. Felhő, C., \& Kundrák, J. (2014). Investigation of the topography of machined surfaces. Applied Mechanics and Materials, 693, 412-417. https://doi.org/10.4028/www.scientific.net/AMM.693. 412

35. Bougharriou, A., Bouzid, W., \& Saï, K. (2014). Analytical modeling of surface profile in turning and burnishing. International Journal of Advanced Manufacturing Technology, 75, 547-558. https://doi.org/10.1007/S00170-014-6168-X

36. Bouzid, W., Tsoumarev, O., \& Saï, K. (2004). An investigation of surface roughness of burnished AISI 1042 steel. International Journal of Advanced Manufacturing Technology, 24, 120-125. https://doi.org/10.1007/s00170-003-1761-4

37. Borysenko, D., Welzel, F., Karpuschewski, B., Kundrák, J., \& Voropai, V. (2021). Simulation of the burnishing process on real surface structures. Precision Engineering, 68, 166-173. https:// doi.org/10.1016/j.precisioneng.2020.12.004

38. Stöckmann, R., \& Putz, M. (2019). Modelling of surface formation mechanism during burnishing of aluminium. Procedia CIRP, 82, 450-454. https://doi.org/10.1016/j.procir.2019.04.033

39. John, M. R. S., Wilson, A. W., Bhardwaj, A. P., Abraham, A., \& Vinayagam, B. K. (2016). An investigation of ball burnishing process on $\mathrm{CNC}$ lathe using finite element analysis. Simulation Modelling Practice and Theory, 62, 88-101. https://doi.org/10. 1016/j.simpat.2016.01.004

40. Kundrak, J., \& Felho, C. (2018). Topography of the machined surface in high performance face milling. Procedia CIRP, 77, 340-343. https://doi.org/10.1016/j.procir.2018.09.030

41. Klauer, K., Eifler, M., Seewig, J., Kirsch, B., \& Aurich, J. C. (2018). Application of function-oriented roughness parameters using confocal microscopy. Eng Sci Technol Int J, 21, 302-313. https://doi.org/10.1016/j.jestch.2018.04.004
Publisher's Note Springer Nature remains neutral with regard to jurisdictional claims in published maps and institutional affiliations.

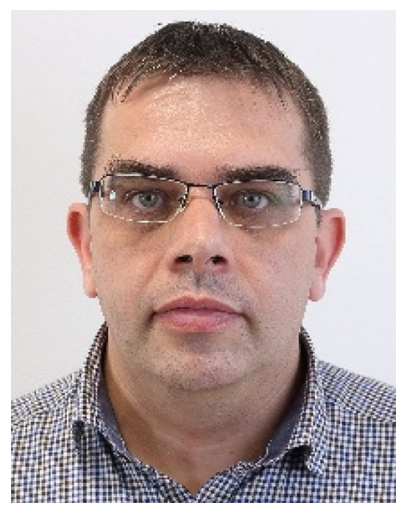

Csaba Felhő received the MSc degree in Information Engineering from the University of Miskolc, Hungary, in 2001 and the Dr.-Ing. degree in Production Engineering from Otto von Guericke University Magdeburg, Germany in 2014, which was one year later nationalized as a $\mathrm{PhD}$ degree in Hungary at the University of Miskolc. His doctoral research focused on prediction of surfaces roughness in different metal cutting processes. He currently works as an associate professor at the Institute of Manufacturing Science, University of Miskolc, Hungary. His current research interests include surface roughness analysis, intelligent sensors, CAD/CAM systems and FEM modelling of metal cutting and diamond burnishing processes.

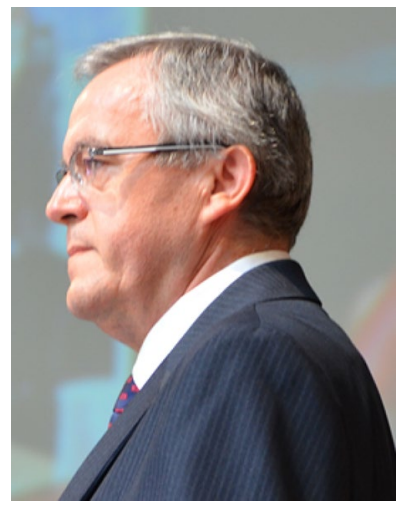

Gyula Varga Associate Professor works at the Institute of Manufacturing Science, University of Miskolc, Hungary from 1990. He was graduated at University of Miskolc, Hungary (1979), as a mechanical engineer, and then he got his PhD degree at the at University of Miskolc (1996). He got a four month "Excalibur scholarship" at UMIST in Manchester, UK in 1993. He participated in number of industrial $\mathrm{R} \& \mathrm{D}$ projects dealing with different problems of production engineering. His main research field is the examination of environmentally conscious machining, and theoretical and experimental investigation of the technology of diamond burnishing. The number of his publication on his research field is more than 265 . 